\title{
Certain Correlates of Burnout among Police Personnel in a Metropolitan City of a Developing Country
}

\author{
${ }^{1}$ Solomen Suresh, ${ }^{2}$ R.N. Anantharaman, ${ }^{3}$ R. Subramanian, ${ }^{4}$ A. Ajitha \\ 1Resurge Chennai, India; \\ 2,3,4Multimedia University, Melaka, Malaysia. \\ r.n.anantharaman@mmu.edu.my
}

\begin{abstract}
Burnout is dysfunctional response to stress. This study investigates the phenomenon of burnout and its relationship to certain demographic, psychological and situational variables. An attempt is also made to find the differences burnout between men and women police. The Maslach Burnout Inventory and demographic profile were administered to a random sample of 220 police personnel in a metropolitan city of a developing country. The results indicated that most of the demographic factors were not related to burnout, however there were significant gender differences in Emotional Exhaustion and Depersonalization dimensions of burnout.
\end{abstract}

Keywords: Burn out, Emotional Exhaustion, Gender difference, Depersonalization.

\section{INTRODUCTION}

Burnout is likely to occur to all those people who have constant public interaction like lawyers, nurses, doctors, teachers, police staff and social workers due their regular contact with public at large. Bradley mentioned in 1969 while studying probationary officers dealing with juvenile delinquents. The term 'burnout' was introduced by Freudenberger in 1974 to refer to a phenomenon which he had observed in himself and in co-workers in the free-clinic movement. According to him burnout is a failure wear- out, or complete exhaustion because of excessive demands on one's energy, strength, or resources. He attributed it to the unceasing pressures of working with emotionally needy and demanding individuals (Freudenberger, 1974). Burnout is characterized by emotional exhaustion, depersonalisation and diminished personal accomplishment (Cordes and Doughterty, 1993). Freudenberger (1974) further tuned the term 'burnout' as a progressive loss of idealism, energy, and purpose as a result of work conditions. Other researchers have developed essentially similar definitions like burnout as 'complex issue with its roots in interpersonal, occupational, organizational, historical and social phenomena (Faber,1983), as a process in which individuals feel blocked from reaching goals and objectives that are important to them (Burisch, 1993).

Burnout involves loss of concern for the people with whom one is working. Physical exhaustion, one of the dimensions of burnout leads to even illness. Ryan (1971) points out that burnout is characterized by an emotional exhaustion. Because of this professionals develop negative feelings, no sympathy and loss of respect for their clients, patients and the public who are receiving care. They develop a cynical and dehumanizing process, the clients or patients are as somehow deserve their problems longer have any positive feelings, sympathy or respect for clients or patients or public. A very cynical and dehumanized perception of these people often develops in which they are labelled in derogatory ways and treated accordingly. As a result of this dehumanizing process, these people are viewed as somehow deserving of their 
problems. They are blamed for their won victimization (Ryan, 1971). They become inhuman towards their clients. This may lead to deterioration in the quality of care or services offered to the clients. The professional whose burnouts are not able to deal effectively with overwhelming emotional stresses of their work. This failure to cope can be manifested in impaired performance and absenteeism. It can also lead to personal problems, drug abuse, alcoholism and mental health problems. Maslach \& Pines (1977) opine that people who are burnout often change professions. They also point out that some of these people seek psychiatric help because they believe to be failure in their personal failures.

Edelwich (1980) posits that people who seek a career in the helping professions are particularly vulnerable to burnout as many enter this field with unrealistic expectations. Such expectations include the belief that the services they provide will decisively improve lives of their clients; they will be highly appreciated by the employing agency and their clients; they will be able to substantially change bureaucracies to be more responsive to client's needs and there may be opportunities for quick advancement in the career. Thus the frustration experienced at work and the gradual un-recognition for the services rendered which is unrealistic and contrary to their expectations, were also contributory factors to burnout.

Burnout is considered as a psychological syndrome that occurs in response to chronic work related stressors (Maslach ET al.2001) and it consists of three dimensions viz emotional exhaustion, depersonalization and reduced personal accomplishment. Emotional exhaustion is characterized by a feeling that one's emotional resources are used up. Depersonalization refers to a cynical, callous and detached attitude towards clients, co-workers and organization. The diminished personal accomplishment is marked by a sense of ineffectiveness and inadequacy in relation to job performance accompanied by negative self-evaluation. Symptoms of burnout can be categorized into five types physical, emotional, behavioural, interpersonal and attitudinal (Kalil Sophia 1988).

In this study we have selected the police personnel who render services to the public day in and day out, throughout the year. Their constant contact with people at large especially criminals may bring more stress in their life. Individual in this profession work intensively, intimately and continually with people who have serious physical, mental, emotional and social problems. The stress associated with processes of helping them involve treating, teaching, counselling and reprimanding, place these professionals at risk for burnout (Rogers \& Dodson 1988). It is necessary to study burnout because it is linked to both individual and work related outcomes, both in general (Maslach et al., 2001) and police officers (Martinussen et al. 2007).

\section{RESEARCH METHODOLOGY}

Burnout measure - The Maslach Burnout Inventory (MBI) developed by Maslach and Jackson (1986) was adopted for the present study. It contained 22 questions and recorded three dimensions of burnout: emotional exhaustion, depersonalization and low personal accomplishment. A high score on the 9 item Emotional Exhaustion subscale reflects feelings of being emotionally overextended and exhausted by one's work. A high score on the 5 item Depersonization subscale indicates a callous and impersonal response toward the recipient of one's service. A low score on the 8 item Personal Accomplishment subscale signifies feelings of incompetence in one's work. Each subscale yields two scores. The first score indicates the frequency with which feelings occur. The response scale for frequency ranges from 0 (never) to 6 (everyday). The second score indicates the intensity of feelings when they occur. In the present study only the frequency with feelings occur alone has been considered. The scale ranges from 1(hardly noticeable to 7 (very strong). Demographic and background questions concerned with age, designation, sex, marital status, education, experience, department like 
Law \& order, traffic or Crime, time pressure, exercise, sick leave availed in the past month and past year and information about sleep.

The sample consisted of 450 police personnel working in urban city in India and includes different categories of police personnel such as Inspectors, Sub-inspectors, Head constables and Constables belonging to both sexes. These personnel belong to six different ranges in Chennai city, which is the fourth largest city in India. Out of 450 questionnaires distributed, 241 questionnaires were returned which works out to 53.6 percent response. When these questionnaire were verified for its completeness, 21 questionnaires were rejected due to their incomplete and defects, leaving 220 valid instruments for test.

\section{RESULTS}

The demographic test results indicated that out of 220 individuals, 201 were men and 19 were women. The mean age was 40 and the standard deviation 7 years. Ninety percent of them were married means only around 22 were not married. Majority of the respondents (66 percent) comprised of sub-inspectors (66 percent) and most of them were promoted from lower grades. The respondents were in service from 2 to 37 years with a mean of 17.6 years. Most of them $(80 \%)$ belong to Law and Order department. A substantial number of respondents (75\%) were engaged in a regular program of exercise ranging from once a week to everyday. Most of them had not availed of sick leave in the past month but the figure slumped to $67 \%$ while considering sick leave not availed in the past year.

The statistical results normative test of burnout indicated that the mean and standard deviations for the three MBI subscales for the frequency dimension are presented in Table 1 below.

Table 1: Means and Standard Deviations

\begin{tabular}{|l|l|l|}
\hline \multirow{2}{*}{ Dimensions of Burnout } & \multicolumn{2}{|c|}{$\mathrm{N}=220$} \\
\cline { 2 - 3 } & Mean & $\mathrm{SD}$ \\
\hline Emotional Exhaustion & 23.22 & 12.03 \\
\hline Depersonalization & 10.9 & 6.10 \\
\hline Personal Accomplishment & 29.18 & 9.36 \\
\hline
\end{tabular}

According to Maslach and Jackson (1986) the scores on the frequency and intensity dimensions of the MBI subscales are interpreted as Low, Moderate or High. These levels are based on score ranges established from data derived from the normative occupational sample. Scores are considered low if they are in the lower third of the normative distribution, moderate if they are in the middle third and high if they are in the upper third. On the basis of the normative data, the mean scores obtained in this study translate to a moderate level of emotional exhaustion and depersonalization and a low level of personal accomplishment. The scores on emotional exhaustion and depersonalization subscales of the present study were remarkably similar to the scores on the same subscales of the normative sample reported by Maslach and Jackson (1981) with less than 2 point difference in each subscale. However there was considerable disparity in scores between the present and normative samples on the Personal Accomplishment subscale indicating more burnout in the present research sample.

The Pearson correlation coefficients between the three MBI subscale scores and other demographic and situational variables are given in Table 2 . 
Table 2 Correlation of Burnout among different variables



The significant correlations are highlighted in table 2 . It can be seen that only two variables viz designation and time pressure are correlated with emotional exhaustion dimension of burnout. There is no relationship between age, marital status, education, experience, branch (police department) locale, daily exercise, sick leave and sleep and three dimension of burnout viz. emotional exhaustion, depersonalisation and personal accomplishment. It can be noted that two burnout subscales, Emotional Exhaustion and Depersonalization show a higher score burnout but for Personal Accomplishment burnout is indicated by lower scores. The correlation between age and three dimensions of burnout is not significant which indicates that there is no relationship between them. Burnout seems to occur among young employees under the age of 30 or 40 and who had less experience (Byrne 1994) whereas Schaufeli and Van Diererndonck (1994) found higher burnout in older age groups in Netherland. The designation of the position is significantly related to emotional exhaustion. The duties and responsibilities increase with the change in position in police department. In police service, many times there will be interference from political bosses and less autonomy in their work. This can lead to stress and burnout.

In order to find out the difference in burnout between men and women police staff, t-test of the mean scores of burnout dimensions of policemen and policewomen were performed. The test results are shown in Table 3.

Table 3 T-test analysis of Gender differences in Burnout among Police Personnel

\begin{tabular}{|c|c|c|c|c|c|c|}
\hline \multirow{3}{*}{ Dimensions } & \multirow{2}{*}{\multicolumn{2}{|c|}{$\begin{array}{c}\text { Policemen } \\
\mathrm{N}=201 \\
\end{array}$}} & \multirow{2}{*}{\multicolumn{2}{|c|}{$\begin{array}{c}\text { Policewomen } \\
\mathrm{N}=19\end{array}$}} & \multirow{3}{*}{ t-value } & \multirow{3}{*}{ p-value } \\
\hline & & & & & & \\
\hline & Mean & SD & Mean & SD & & \\
\hline Emotional Exhaustion & 22.54 & 11.80 & 28.03 & 12.74 & -2.26 & $0.029 *$ \\
\hline Depersonalization & 10.35 & 5.63 & 14.77 & 7.72 & -3.08 & $0.004^{*}$ \\
\hline Personal Accomplishment & 28.97 & 10.20 & 30.64 & 6.90 & -1.18 & 0.244 \\
\hline
\end{tabular}

$* p<0.05 \quad * * p<0.01$

The t-test indicates gender differences in Emotional Exhaustion $(\mathrm{P}<0.05)$ and Depersonalization $(\mathrm{p}<0.01)$. Policewomen are appeared to be more burnout than policemen not with-standing the difference in Personal Accomplishment being insignificant. 


\section{DISCUSSION AND CONCLUSIONS}

The present study is an attempt to elucidate the relationship between burnout and certain demographic factors. The analyses clearly indicate that age was not correlated with burnout. Although no specific hypothesis was developed it was expected that the age would be negatively related to burnout since normative data suggests that one of the benefits of age is lower burnout. Stevens and O'Neill (1983) found, that in a study of workers in developmentally disabled population, decreases on Emotional exhaustion and Depersonalization with age. However these were accompanied by decreases rather than increases on Personal Accomplishment. Lowered burnout may arise from the replacement over time of less effective coping strategies with more effective ones. The discrepant results imply that coping skills of police personnel were inadequate irrespective of age.

In this study designation appeared to influence Emotional Exhaustion. Police personnel higher up in the hierarchy experienced more Emotional Exhaustion than their subordinates. Could it be that increased responsibility in conjunction with intensive interaction daily with people having different and at the same time serious problems of varied nature leads to burnout? Earlier researcher Burke and Greenglass (1989) noted a reverse trend in burnout in teaching with regard to designation. Teachers reported greater burnout than did department heads or principals. However a more comprehensive examination of the relationship of designation to burnout is recommended to warrant the existence of the positive relationship observed in the present study.

Earlier researchers (Mor \& Laliberte, 1984 Maslach \& Jackson 1981) linked education with a greater degree of burnout, whereas other researchers (Rogers \& Dodson 1988; burke \& Greenglass, 1989) evidenced contrary. In this study education was not associated with burnout. It is presumed that the duration of exposure to a stressful situation would increase burnout. Nonetheless, neither the effects of long experience in developmental disabilities (Stevens \& O'Neill, 1983) nor the effects of long experience in one position in child care (Maslach \& Pines, 1977) supported this logic. Therefore duration of exposure as represented by years of work in police service was not linked to burnout.

The experience of time pressure, that of seldom having enough time to do all that one has to do, was associated with Emotional exhaustion. The police staff can be called for duty at any time even during holidays. Most of the time they have to work more than prescribed work hours, since the ratio of police staff to public in India is very low. In addition, they have to provide security to political leaders, religious leaders and VVIPs in public meetings and other functions. Some of the police personnel are posted at the senior officers, VVIPs and foreign diplomat's residences to provide security services which requires more than the prescribed working hours. They have very little time to be with their families and take part in their social functions. This may result in strained relationships with family members leading to alcoholism, divorce and restless life. Further the bureaucracy and red tape in police organisation coupled with no time for police personnel for leisure activities or for social life. As a result, there is deterioration in performance which in turn results in a higher backlog of personal and professional work. Thus a vicious cycle is set into motion ultimately leading to high stress and to burnout.

Women police staff seems to have higher level of emotional exhaustion and less personal accomplishment when compared to men police staff (Silbert, 1982, Etzion and Pines, 1986). The present study is supported by Him, Zao and Archhold (2002) and Berg et al (2003) who found that female police officers had higher level of burnout than male police officers. Other researchers for example Kop et al. (1999), Newman Rucker-Reed (2004) and Martinussen et al (2007), McCarty et al. (2007) reported no difference between them in burnout. Greenglass (1991) opines that gender is confounded with occupational role and hierarchical position. 
Compared to men, women often less occupy supervisory roles in organisations. This makes them to have less access to job related rewards such as high income, social status and autonomy. The number of women police staff is very negligible in Indian context. Recently only women are willing to serve in police force and they are being recruited by the federal and state governments. Since they are less in numbers and have less opportunities for social support mentoring and less promotional changes in police service in India could be the reason for male domination in this profession and lesser number of women force in police service.

Similarly Streams and Moore (1990) found that female officers experienced more burn out than male staff in the Royal Canadian Mounted Police (RCMP). On the other hand they also reported on personal accomplishment (PA) both male and female officers experienced high burnout. The police women in the present study manifested a similar trend with regard to burnout.

The summary of analysis indicates that the relations among burnout and demographic data suggest that most demographic factors were not associated with burnout. The results of earlier studies also indicated inconsistency among them. The present study findings are consistent with previous research study of Maslach and Jackson, 1981, implicating the primary role of job and work setting characteristics with individual difference playing a lesser role in psychological burnout. It can be stated from organisational perspective, research on burn-out is important, both in terms of responsibility of police organisations to guarantee the well-being of police staff and in terms of maintaining and improving organisational performance, (Jessica, 2007). In India the government has to recruit more police staff to increase public and police ratio. This can enable the police officers to have more time for themselves and for social life.

\section{References}

Adler, N. J. (1983). Cross-Cultural Management Research: The Ostrich and the Trend. Academy of Management Review, 8, 226-232.

Berg, A.M., Hem, E., Lau, B., Loeb \& Ekeberg. (2003). Suicidal ideation and attempts in Norweyian Police. Suicide and Life Threatening Behaviours, 33, $302-312$.

Blau, G., Fertig, J., Tatum, D., Connaughton, S., Park, D., and Marshall, K. (2010), "Further scale refinement for emotional labor: exploring distinctions between types of surface versus deep acting using a difficult client referent", Career Development International, Vol. 15 pp.188-216

Blau, G. Bentley, M.A, and Purcell, E.J. (2012) "Testing the impact of emotional labor on work exhaustion for three distinct emergency medical service (EMS) samples", Career Development International, Vol. 17 Iss: 7, pp.626- 645 .

Bradley, H. B. (1969). Community based treatment for young adult offenders. Crime and Delinquency, 15, 359370 .

Burisch, M. (1993). In search of theory: some ramifications on the nature and etiology of burn-out: In Schaufeli, W.B., Maslach, C and Marek, J., (Eds) Professional burn-out. Recent developments in theory and research, Taylor and Francis, Washington D C.

Burke, R.J., and Greenglass, E. (1989). Sex differences in psychological burnout in teachers. Psychological Reports, $65,55-63$.

Burke, R. J., Shearer, J., and Deczca, G. (1984). Burnout among men and women in Police Work: An examination of the cherniss model. Journal of Health and Human Resource Administration, 7, 162 - 188.

Byrne, B.M. (1994). Burnout testing for the validity, replication and invariance of casual structure across elementary, intermediate and secondary teachers. American Education Research Journal, 32, 654 - 73. 
Cheong, J. and Yun, I. (2010) Victimization, stress and use of force among South Korean police officers, Policing: An International Journal of Police Strategies \& Management Vol. 34 No. 4, 2011, pp. 606-624.

Cordes, C.L., and Dougherty, T.W. (1993). A review and an integration of research and job burnout. Academy of Management Review, 18, 4, 621 - 656.

Digram, J. T., Barrera, M. Jr., and West, S. G. (1986). Occupational stress, social support and burn out among correctional officers. American Journal of Community Psychology, 14, 177 - 193.

Edelwich, J and Brodsky, A. (1980). Burnout stages of disillusionment in the helping professions. Human Sciences Press, New York, NY.

Etizon, D., and Pines, A. (1986). Sex and culture in burnout and coping among human service professionals: A social psychological perspective. Journal of Cross-cultural Psychology, 17, 191 - 209.

Faber, B. A. (1983). Stress and burnout in the human service professions. Pergamon Press, New York.

Freudenkerger, H.J. (1974). Staff Burnout. Journal of Social Issues, 30, 159 - 165.

Greenglass (1991). Burnout and gender: Theoretical and organisation implications. Canadian Psychology, 32, 562-574.

Greenglass, E., and Burke, R.J. (1988). Work and family precursors of burnout in teachers-sex differences. Sex Roles, 18, $215-229$.

He, Zao and Archbold (2002). Gender and Police Stress: the convergent and divergent impact of work environment, work-family conflict and stress coping mechanisms of female and male police officers. Policing, 25, 687- 707.

Jessica, L. (2007). Burnout and engagement in probationary Police Officers: A scoping paper. Australian Centre for Policing Research.

Johnson, B. (1991). Job stress among police officers: Gender Comparison. Police Studies, 14, 12 - 16.

Kahill, S. (1988), "Symptoms of Professional burnout. A review of the empirical evidence". Canadian Psychology, $29,3,284-297$.

Kop.N. Euwenna, M., and Shaufeli. (1999). Burnout, job stress and violent behaviour among Dutch Police Officers. Work and Stress, 13, 326 - 340.

Laschinger, H., Finegan, J. (2005), "Empowered nurses for work engagement and health in hospital settings", Journal of Nursing Administration, Vol. 35 pp.439-49.

Loo, R. (1999). Burnout among Canadian Police Managers. International Journal of Organizational Analysis, 2, 406 $-417$.

Martinussen, M., Richardson, A. M., and Burke, R. J. (2007). Job demands, job resources and burnout among police officers. Journal of Criminal Justice, 35, 3, 239 - 249.

Maslach, C., and Jackson, S. E. (1981). The measurement of experienced burnout. Journal of Occupational Behaviour, 2, 99 - 113.

Maslac, C., and Pines, A. (2005). One burnout measure shot version. International Journal of Stress Management, $12,78-87$.

Maslach, G., Schaufeli and Leiter, M. P. (2001). Job burnout. Annual Review of Psychology, 52, 397 - 422.

McCarty, W. P., Zaho, J.S., and Garland, B. E. (2007). Occupational stress and burnout between male and female police officers. An International Journal of Police Strategies \& Management, 30, 4, 672 - 691.

Melamed, S., Shirom, A., Toker, S., Berliner, S., and Shapira, I. (2006), "Burnout and risk of cardiovascular disease: evidence, possible causal paths, and promising research directions", Psychological Bulletin, Vol. 132 pp.327-53.

Mor, V., and Laliberte, L. (1984). Burnout among hospice staff. Health and Social Work. 9, 273 - 284. 
Suresh, S., Anantharaman, R. N., Subramanian, R., \& Ajitha, A. (2014). Certain Correlates of Burnout among Police Personnel in a Metropolitan City of a Developing Country. Archives of Business Research, 2(6), 1-8.

Newman, D.W., and Rucker - Reed, M.L. (2004). Police stress, state-wait anxiety and stressors among US marshals. Journal of Criminal Justice, 32, $631-641$.

Pines, A., and Maslach, C. (1980). Combating staff burn-out in a day care centre- A case study. Child Care Quarterly, $9,5-16$.

Rogers, J.C., and Dodson, S.C. (1988). Burnout in Occupational therapists. American Journal of Occupational Therapy, 42, $787-792$.

Ryan, W. (1971). Blaming the Victim. Pantheon Books, New York.

Schaible, L.M., and Gecas, V. (2010). The impact of emotional labour and value dissonance on burnout among police officers. Police Quarterly, 13 (3), 316 - 341.

Schaufeli and Van Diererndonck. (1994). Burnout the measurement of a construct: The Dutch version of Maslach burnout inventory. Gedrage en Gerondheid, 22, 153 - 172.

Silbert, M.H. (1982). Job stress and burnout and new police officers. Police Chief, 49(6), $46-68$.

Stearns, G. M., and Moore, R. J. (1990). Job burnout in the Royal Canadian Mounted Police: Preliminary findings from Saskatchewan sample -. Journal of Police Science and Administration, 17, 183 - 193.

Stearns, G. M., and Moore, R. J. (1993). The physical and psychological correlates of job burnout in the Royal Canadian Mounted Police. Canadian Journal of Criminology, 35, 125 - 148.

Stevens, G. B., and O' Neil, P. (1983). Expectation and burn-out in the developmental disabilities field. American Journal of Community Psychology, 11, 615 - 627. 